\title{
Stiffness of vascular smooth muscle cells from monkeys studied using atomic force microscopy
}

\author{
Yi Zhu ${ }^{1,2}$ \\ ${ }^{1}$ Department of Medicine, University of Alabama-Birmingham, Birmingham, AL, \\ 35294 \\ ${ }^{2}$ Dalton Cardiovascular Research Center, University of Missouri-Columbia, \\ Columbia, MO, 65211 \\ Email address: yalezhuphd@gmail.com
}

\begin{abstract}
Vascular smooth muscle cells (VSMC) are the main cellular components of blood vessel walls and bear external mechanical forces caused by blood flow and pressure. In this report, we have verified the following hypothesis through experiments: The increase in VSMC stiffness may be mainly due to changes in vascular stiffness due to aging. Although aging enhances the stiffness and adhesion of VSMC, there is no significant difference in apparent elastic modulus and adhesion between the VSMC obtained by male and female. The effect of aging through the ECM-integrin-cytoskeleton axis is related to increased VSMC stiffness and matrix adhesion rather than gender.
\end{abstract}

Key words: Atomic force microscopy; vascular smooth muscle cell; age; elasticity; monkey 


\section{Introduction}

Most prior studies have utilized either indirect measurements of vascular stiffness or examined isolated vessel preparations. Additionally, most prior work has focused on the extracellular matrix (ECM) or endothelial control, as the source of the changes in vascular stiffness (Lakatta E.G., et al., 2002a and 2002b; Mitchell G.F., et al., 2004 and 2007; Haddock R.E., et al., 2005; Qiu et al., 2007). These ECM changes were primarily seen as an increase in total collagen and a decrease in elastin (Qiu H. Y., et al., 2007; Hong Z.K., et al., 2015). VSMCs are the main cellular components of blood vessel walls and bear external mechanical forces caused by blood flow and pressure. The aging process reduces the number of VSMCs in arteries, and the remaining VSMCs are enlarged in cell size to work harder (Briones A. M., et al., 2010; Lee H.Y., et al., 2010). The single VSMC mechanical characteristics and behavior is chiefly considered to play a key role in the development of vascular diseases (Zhu Y., et al., 2018 and 2019). Cytoskeletal action and role in VSMCs include contractile filament cycling for the actin and myosin cross-bridge and remodeling of cytoskeletal architecture and construction to employ and perform the mechanical forces (Levental K.R., et al., 2009; Niland S., et al., 2011). The cytoskeletal behaviors flexibly and livelily support and sustain VSMC elastic and adhesive properties to respond and regulate vascular physiological functions. More importantly, the cytoskeleton is physically and functionally participated and joined to the cell adhesive process. VSMC imposes the regulation and control of ECM assembly, composition and architecture through cell adhesion, and they are likely playing an important role in the ECM stiffening associated with aging. Meanwhile, VSMCs also can conversely alter their signaling state to reflect the rigidity of the ECM through adhesions to the ECM cells. Thus, the relationship is made complex by the changing and lively two-way interaction between ECM-adhesion sitecytoskeleton (Staiculescu M.C., et al., 2014). The AFM probe deflection and applied force can be used to determine cellular elasticity by an AFM probe indenting the surface of the cell (Sader J. E., et al., 1999; Labernadie A., et al., 2010). The AFM probe is functionalized with a ligand, and then the adhesion of the AFM probe to the cell surface can be used to evaluate cell adhesive interactions and this has been a successful application for studies of VSMC-ECM interaction (Sun Z., et al., 2005, 2008 and 2009; Hong Z., et al., 2015). For these studies we used atomic force microscopy and imaging to estimate and evaluate Young's modulus of elasticity and adhesion in aortic smooth muscle cells derived from groups of old and young primates. Our 
studies have revealed some very novel findings regarding changes in smooth muscle cell mechanical characteristics that occur during aging. We had observed that smooth muscle cell stiffness and adhesion to the extracellular matrix is significantly increased in old monkey cells compared to those of young counterparts.

An important feature of this investigation was the use of the non-human primate model (M. fascicularis). The primate model has a closer phylogenetic proximity to humans and also exhibits an aging process that occurs more gradually over 20-30 years, vs 1-2 years in rodents. The mechanical properties of the VSMCs were measured directly in vitro using AFM. The apparent Young's modulus was significantly increased in VSMCs from old male and female monkeys compared to young male and female counterparts. Moreover, the measured adhesion force was significantly increased in VSMCs from old male and female monkeys compared to young male and female monkeys. However, the apparent elastic modulus and adhesion force were not significantly different between male and female in the same aging group. The pan actin intensities of VSMCs using immunostaining analysis and the cell sizes of VSMCs from the old group were higher than those from the young group both in male and female monkeys. The apparent values were not significantly different between male and female in the same aging. The cell heights were not significantly changed due to aging and gender difference. Our results demonstrated that the intrinsic mechanical properties of VSMCs contribute to the increased vascular stiffness associated with aging and without gender.

\section{Materials and Methods}

\subsection{Animal model}

In this study young $(6.4 \pm 0.1$ years) and old (25 \pm 0.4 years) monkeys (Macaca fascicularis) ( $n=3 /$ group) were used and maintained in the Guide for the Care and Use of Laboratory Animals (NIH 85-23, revised 2011).

\subsection{VSMC isolation and culture}

VSMCs from thoracic aorta of monkeys were enzymatically isolated and used at passages 2 to 4 . All external fat, connective tissue, adventitia and endothelial layer were carefully detached and removed. The prior publications provided the detail methods (Qiu H.Y., et al., 2010; Zhu Y., et al., 2012; Sehgel N.L., et al., 2013).

\subsection{AFM imaging, VSMC stiffness and force measurement}


The topographical images of VSMC in this chapter were operated in contact mode by an AFM instrument, which is a Bioscope System (model IVa, Veeco Mertrology Inc.) mounted on an Olympus IX81 microscope (Olympus Inc.), and the AFM probe scanned across the cell surface (35 to $40 \mathrm{~mm} / \mathrm{s}$ ) with a tracking force of 300 500 pN. Transverse VSMC stiffness was measured in force mode using silicon nitride cantilevers (Trache A., et al., 2008; Hong Z.K., et al., 2012; Sehgel N.L., et al., 2015), and the AFM probe was repeated to approach and retract from the cell surface at $0.5 \mathrm{~Hz}$ (tip speed $800 \mathrm{~nm} / \mathrm{s}$ ) to collect 15-20 force curves from the same site on each VSMC (30-40 s of recording). 10-20 cells were randomly selected and the AFM probe indented at a site midway between the nucleus and cell margin (150-400 force curves per cell) for each experiment. Young's modulus theory was applied to interpret and translate the recorded approach-rapture force curve into the AFM force-indentation description and statement for the quantification of VSMC elasticity. The calculation of the elastic modulus was:

$$
F=\frac{2 E \delta^{2}}{\pi\left(1-v^{2}\right)} \tan (\alpha)
$$

where the indentation force $(\mathrm{F})$ was stated and described using Hooke's law $(\mathrm{F}=\kappa \Delta \mathrm{x}, \kappa$ and $\Delta \mathrm{x}$ denote the AFM probe's spring constant and the probe's apparent deflection). The indentation depth $(\delta)$ is identified from the difference in the AFM piezo movement in $\mathrm{z}$ direction and the AFM probe deflection. E is the Young's modulus of experimental cell as the value of elasticity, and $v$ denotes 0.5 for cell as the Poisson ratio. The numerical $\alpha$ is the semi-included angle of the cone for a pyramidal tipped probe and determined by the probe shape (MLCT, Veeco Mertrology Inc., Santa Barbara, CA) (Sun Z, et al., 2012; Hong Z., et al., 2014). An authoritative software NforceR is often applied to quantitatively analyze the apparent forcedistance curves (Trzeciakowski J.P. et al., 2006).

$\beta 1$ integrin was identified on the VSMC surface using AFM probes labeled with fibronectin (1mg/ml) (Invitrogen, Grand Island, NY). Probes were operated in force-mode and repeated to indent and retract from the cell surface and specific adhesions detected as sharp shifts in the retraction curves using automated software (NforceR) (Trzeciakowski, J.P., et al., 2006). With each probe, 10 randomly selected cells were sampled 50-60 times to collect approximately 500-600 force curves for analysis. 


\subsection{Immunostaining analysis}

Isolated VSMCs were cultured and grown for 48 hours on glass substrate dishes under $37^{\circ} \mathrm{C}$ and $5 \% \mathrm{CO}_{2}$ environment, and then fixed in $4 \%$ formaldehyde. The fixed cells were permeabilized with $0.1 \%$ Triton-X 100 for 5 minutes, rinsed and incubated with the primary antibodies overnight. Rinsed and washed 6 times using an antibody buffer, the cells were stained with the fluorescent secondary antibody. The cells were imaged by confocal microscopy for pan actin and $\alpha 5 \beta 1$-integrin.

\subsection{VSMC cell area and height measurement}

Analyzed and measured VSMC cell area and height from AFM deflection images using the bioscope software (a Bioscope System, model IVa, Veeco Mertrology Inc.).

\subsection{Statistical analysis}

Data are described as mean \pm SEM for the number of samples reported in each figure legend. Statistically significant differences between young and old monkeys were identified using Student's t-test. A value of $\mathrm{P}<0.05$ was considered significant.

\section{Results}

\subsection{VSMC AFM and confocal microscopic image and topography}

To study VSMC physical character, we first observed and compared single cell area and height. From AFM image data (Figure 1), the male monkey cell area of old (10 cells from 3 animals) vs. young (10 cells from 3 animals) was $10,317 \pm 24 \mu \mathrm{m}^{2}$ vs. $10,167 \pm 9 \mu^{2}$ and the male monkey cell height of old (17 cells from 3 animals) vs. young (10 cells from 3 animals) was $3366 \pm 214 \mathrm{~nm}$ vs. $3518 \pm 124 \mathrm{~nm}$. And the female monkey cell area of old (10 cells from 3 animals) vs. young (10 cells from 3 animals) was $10,285 \pm 30 \mu \mathrm{m}^{2}$ vs. $10,183 \pm 8 \mu \mathrm{m}^{2}$ and the female monkey cell height of old (14 cells from 3 animals) vs. young (14 cells from 3 animals) was $3171 \pm 134 \mathrm{~nm}$ vs. $3366 \pm 175 \mathrm{~nm}$, respectively. The cell area of old monkeys was larger than that of young monkeys $(\mathrm{P}<0.05)$, and there was no significant difference between male and female in both old and young. Despite the differences of monkey age and gender, the cell height did not show a significant difference. The VSMCs of thoracic aorta from subject monkeys were also investigated by confocal microscopy, pan actin data was listed in Figure 2. From the 
immunostaining intensity analysis and comparison, the old male monkey VSMCs (8 cells from 3 animals) were higher than those of young male monkey (12 cells from 3 animals), and the old female monkey VSMCs (12 cells from 3 animals) were higher than those of young female monkey (22 cells from 3 animals), but in the same age group, male and female cells were not different in fluorescent intensity. Moreover, immunostaining intensity for $\alpha 5 \beta 1$-integrin in cultured VSMCs from thoracic aorta of monkeys was shown in Figure 3. The old male monkey VSMCs (11 cells from 3 animals) were higher than those of young male monkeys (17 cells from 3 animals), and the old female monkey VSMCs (19 cells from 3 animals) were higher than those of young female monkeys (16 cells from 3 animals), respectively. Interestingly, in the same age group, male and female cells were not different in fluorescent intensity.

\subsection{Elasticity and ECM protein-integrin adhesion}

Single VSMC elasticity was measured using AFM nanoindentation. As shown in Figure 4, the apparent elastic modulus was significantly higher in VSMCs from old $(42.6 \pm 3.4 \mathrm{kPa} ; 11$ cells from 3 animals) compared with young (11.3 $\pm 1.6 \mathrm{kPa} ; 6$ cells from 3 animals) male monkeys. Moreover, the apparent elastic modulus was significantly higher in VSMCs from old (50.6 $\pm 4.6 \mathrm{kPa} ; 7$ cells from 3 animals) compared with young $(12.8 \pm 1.3 \mathrm{kPa} ; 8$ cells from 3 animals) female monkeys. These elasticity data demonstrate that VSMCs from old monkeys are inherently stiffer than those from young monkeys. In addition, AFM probes coated with fibronectin to measure the adhesion behavior of old versus young VSMC integrin $\alpha 5 \beta 1$ (Figure 4), and adhesive forces were also enhanced in old VSMCs, as evidenced by their increased adhesion to FN-coupled AFM probes. The measured force was significantly increased $(\mathrm{p}<0.05)$ in VSMCs from old male (77.6 $\pm 12.4 \mathrm{pN}$; 11 cells from 3 animals), and old female monkeys $(89.5 \pm 7.8 \mathrm{pN} ; 11$ cells from 3 animals) compared to young male $(43.5 \pm 3.8 \mathrm{pN} ; 6$ cells from 3 animals), and young female monkeys (54.2 $\pm 6.0 \mathrm{pN} ; 6$ cells from 3 animals). In the same age group, male and female cells were not also different in stiffness and adhesive force.

\section{Discussion}

Our prior research showed the abundance of alpha-smooth muscle actin in cytoskeleton of the old monkey VSMCs (Qiu H.Y. et al., 2010; Zhu Y. et al., 2012). From the AFM image data, the area of single VSMC is significantly higher in old compared to young 
monkeys, thus the physical character of single old monkey VSMC is different from that of young one. A single vascular smooth muscle cell from male monkeys (Macaca fascicularis) was measured with AFM indentation method, and the old VSMC is obviously harder than the young one in elasticity. Meanwhile, the alpha-SMA of cytoskeleton mainly contributes to the inherent mechanical feature of VSMC (Figure2B).

The adhesion force significantly enhanced in old compared to young monkeys due to old monkeys' higher expression of $\beta 1$-integrin (Qiu H.Y. et al., 2010; Zhu Y. et al., 2012). Fibronectin specifically binds with $\beta 1$-intergrin (Parsons J.T., et al., 2010; Staiculescu M.C., et al., 2013). The $\alpha$-SMA is an important component of the ECM-integrin-cytoskeltal axis responsible for mechanosensation, -transduction and -transmission (Geiger B., et al., 2001; Galbraith C.G., et al., 2002 and 2007). Meanwhile, the $\beta 1$-integrin, which is one of transmembrane proteins for the interaction between the ECM protein and the cytoskeleton, provides an important mechanical role and association with the extracellular environment (Schwartz M.A., et al., 2002; Staiculescu M.C., et al., 2014; Han S.J. et al., 2015). Interestingly, the apparent values of stiffness of VSMCs between male and female of young monkeys were closed. In summary, we demonstrate that aging is associated with increased VSMC stiffness and cell- matrix adhesion via the ECM-integrin-cytoskeltal axis responsibility rather than gender.

\section{Reference}

Briones A. M., Arribas S.M., Salaices, M. Role of extracellular matrix in vascular remodeling of hypertension. Current Opinion in Nephrology \& Hypertension, 2010, 19(2), 187-194.

Galbraith C.G., Yamada K.M., Sheetz M.P. The relationship between force and focal complex development. The Journal of Cell Biology, 2002, 159(4), 695-705.

Galbraith C.G., Yamada K.M., Galbraith J.A. Polymerizing actin fibers position integrins primed to probe for adhesion sites. Science, 2007, 315 (5814), 992-995.

Geiger B., Bershadsky A., Pankov R., Yamada K.M. Transmembrane extracellular matrixcytoskeleton crosstalk. Nature Reviews Molecular Cell Biology, 2001, 2, 793-805.

Haddock R.E., Hill C.E. Rhythmicity in arterial smooth muscle. The Journal of Physiology, 2005, 566(3), 645-656.

Han S.J., Oak Y., Groisman A., Danuser G. Traction microscopy to identify force modulation in subresolution adhesions. Nature Methods, 2015, 12(7), 653-656. 
Hong Z., Sun Z., Li Z., Mesquitta W.T., Trzeciakowski J.P., Meininger G.A. Coordination of fibronectin adhesion with contraction and relaxation in microvascular smooth muscle.

Cardiovascular Research, 2012, 96(1), 73-80.

Hong Z., Sun Z., Li M., Li Z.H., Bunyak F., Ersoy I., Trzeciakowski J.P., Staiculescu M.C., Jin M., Martinez-Lemus L., Hill M.A., Palaniappan K., Meininger G.A. Vasoactive agonists exert dynamic and coordinated effects on vascular smooth muscle cell elasticity, cytoskeletal remodelling and adhesion. Journal of Physiology, 2014, 592(6), 1249-1266.

Hong Z., Reeves K.J., Sun Z., Li Z., Brown N.J., Meininger G.A. Vascular smooth muscle cell stiffness and adhesion to collagen I modified by vasoactive agonists. PloS One, 2015, 10(3), e0119533.

Labernadie A., Thibault C., Vieu C., Maridonneau-Parini I., Charrière G.M. Dynamics of podosome stiffness revealed by atomic force microscopy. The Proceedings of the National Academy of Sciences USA, 2010, 107(49), 21016-21021.

Lakatta E.G. Age-associated cardiovascular changes in health: impact on cardiovascular disease in older persons. Heart Failure Reviews, 2002a, 7(1), 29-49.

Lakatta E.G., Sollott S.J. Perspectives on mammalian cardiovascular aging: humans to molecules. Comparative Biochemistry and Physiology - Part A: Molecular \& Integrative Physiology, 2002b, 132(4), 699-721.

Lee H.Y., Oh B.H. Aging and arterial stiffness. Circulation Journal, 2010, 74(11), 2257-2262.

Levental K.R., Yu H., Kass L., Lakins J.N., Egeblad M., Erler J.T., Fong S.F., Csiszar K., Giaccia A., Weninger W., Yamauchi M., Gasser D.L., Weaver V.M. Matrix crosslinking forces tumor progression by enhancing integrin signaling. Cell, 2009, 139(5), 891-906.

Mitchell G.F., Parise H., Benjamin E.J., Larson M.G., Keyes M.J., Vita J.A., Vasan R.S., Levy D. Changes in arterial stiffness and wave reflection with advancing age in healthy men and women: the Framingham Heart Study. Hypertension, 2004; 43(6), 1239-1245.

Mitchell G.F., Guo C.Y., Benjamin E.J., Larson M.G., Keyes M.J., Vita J.A., Vasan R.S., Levy D. Cross-sectional correlates of increased aortic stiffness in the community: the Framingham Heart Study. Circulation, 2007, 115(20), 2628-2636.

Niland S., Westerhausen C., Schneider S.W., Eckes B., Schneider M.F., Eble J.A.

Biofunctionalization of a generic collagenous triple helix with the $\alpha 2 \beta 1$ integrin binding site allows molecular force measurements. The International Journal of Biochemistry \& Cell Biology, 2011, 43(5), 721-731.

Parsons J.T., Horwitz A.R., Schwartz M.A. Cell adhesion: integrating cytoskeletal dynamics and cellular tension. Nature Reviews Molecular Cell Biology, 2010, 11(9), 633-643.

Qiu H.Y., Depre C., Ghosh K., Resuello R.G, Natividad F.F., Rossi F., Peppas A., Shen Y.T., Vatner D.E., Vatner S.F. Mechanism of gender-specific differences in aortic stiffness with aging in nonhuman primates. Circulation, 2007, 116(6), 669-676. 
Qiu H.Y., Zhu Y, Sun Z., Trzeciakowski J.P., Gansner M., Depre C., Resuello Ranillo R.G., Natividad F.F., Hunter W.C., Genin, G.M., Elson, E.L., Vatner, D.E., Meininger G.A., Vatner S.F. Vascular Smooth Muscle Cell Stiffness as a Mechanism for Increased Aortic Stiffness with Aging. Circulation Research, 2010, 107(5), 615-619.

Sader J. E., Chon J. W. M., Mulvaney P. Calibration of rectangular atomic force microscope cantilevers. Review of Scientific Instruments, 1999, 70(10), 3967-3969.

Schwartz M.A., Ginsberg M.H. Networks and crosstalk: integrin signalling spreads. Nature Cell Biology, 2002, 4(4), E65-E68.

Sehgel N.L., Zhu Y., Sun Z., Trzeciakowski J.P., Hong Z., Hunter W.C., Vatner D.E., Meininger G.A., Vatner S.F. Increased vascular smooth muscle cell stiffness: a novel mechanism for aortic stiffness in hypertension. American Journal of Physiology-Heart and Circulatory Physiology, 2013, 305(9), H1281-H1287.

Sehgel N.L., Sun Z., Hong Z., Hunter W.C., Hill M.A., Vatner D.E., Vatner S.F., Meininger G.A. Augmented vascular smooth muscle cell stiffness and adhesion when hypertension is superimposed on aging. Hypertension, 2015, 65(2), 370-377.

Staiculescu M.C., Galiñanes E.L., Zhao G., Ulloa U., Jin M., Beig M.I., Meininger G.A., Martinez-Lemus L.A. Prolonged vasoconstriction of resistance arteries involves vascular smooth muscle actin polymerization leading to inward remodelling. Cardiovascular Research, 2013, 98(3), 428-436.

Staiculescu M.C., Ramirez-Perez F.I., Castorena-Gonzalez J.A., Hong Z., Sun Z., Meininger G.A., Martinez-Lemus L.A. Lysophosphatidic acid induces integrin activation in vascular smooth muscle and alters arteriolar myogenic vasoconstriction. Frontiers in Physiology, 2014, 5, 413.

Sun Z., Martinez-Lemus L.A., Trache A., Trzeciakowski J.P., Davis G.E., Pohl U., Meininger G.A. Mechanical properties of the interaction between fibronectin and $\alpha 5 \beta 1$-integrin on vascular smooth muscle cells studied using atomic force microscopy. American Journal of Physiology Heart and Circulatory Physiology, 2005, 289 (6), H2526-H2535.

Sun Z., Martinez-Lemus L.A., Hill M.A., Meininger G.A. Extracellular matrix-specific focal adhesions in vascular smooth muscle produce mechanically active adhesion sites. American Journal of Physiology-Cell Physiology, 2008, 295 (1), C268-C278.

Sun Z., Juriani A., Meininger G.A., Meissner K.E. Probing cell surface interactions using atomic force microscope cantilevers functionalized for quantum dot-enabled Forster resonance energy transfer. Journal of Biomedical Optics, 2009, 14(4), 040502.

Sun Z., Li Z., Meininger G.A. Mechanotransduction through fibronectin-integrin focal adhesion in microvascular smooth muscle cells: is calcium essential? American Journal of Physiology Heart and Circulatory Physiology, 2012, 302(10), H1965-H1973.

Trache A., Meiniger G.A. Atomic force microscopy (AFM). Current Protocols in Microbiology, 2008, 8, 2C.2.1-2C.2.17. 
Trzeciakowski, J.P., Meininger G.A. NForceR, A software program for atomic force microscopy data analysis and display package, copyright October 10, 2006. Registration Number TXu1-328659.

Zhu Y., Qiu H., Trzeciakowski J.P., Sun Z., Li Z., Hong Z., Hill M.A., Hunter W.C., Vatner D.E., Vatner S.F., Meininger G.A. Temporal analysis of vascular smooth muscle cell elasticity and adhesion reveals oscillation waveforms that differ with aging. Aging Cell, 2012, 11(5), 741750 .

Zhu Y., He L., Qu J., Zhou Y. Regulation of Vascular Smooth Muscle Cell Stiffness and Adhesion by $\left[\mathrm{Ca}^{2+}\right]_{\mathrm{i}}$ : an Atomic Force Microscopy-Based Study. Microscopy and Microanalysis, 2018, 24(6), 708-712.

Zhu Y., Qu J., Zhang F., Zhou Z, Yang S., Zhou Y. Calcium in Vascular Smooth Muscle Cell Elasticity and Adhesion: Novel Insights into the Mechanism of Action. Frontiers in Physiology, 2019, 10, a00852 (1-8). 


\section{Figure Legends}

Figure.1 Topographic characterizations of old and monkey VSMCs (A) VSMC area from thoracic aorta of old (male $n=15$, female $n=11$ ) and young (male $n=10$, female $n=10$ ) monkeys. *, $\mathrm{P}<0.05$ old versus young monkeys. $\mathrm{p}>0.05$ male vs female. (B) VSMC height from thoracic aorta of old (male $n=17$, female $n=14$ ) and young (male $n=10$, female $n=14$ ) monkeys. $P>0.05$ old versus young monkeys. p>0.05 male vs female. (C) AFM deflection images of thoracic aorta vascular smooth muscle cells from old and young male monkeys. (D) AFM deflection images of thoracic aorta vascular smooth muscle cells from old and young female monkeys.

Figure.2 (A) Immunostaining intensity for pan actin in cultured VSMCs from thoracic aorta of old (male $\mathrm{n}=8$, female $\mathrm{n}=12$ ) and young (male $\mathrm{n}=12$, female $\mathrm{n}=22$ ) monkeys. *, $\mathrm{P}<0.05$ old versus young monkeys. p>0.05 male vs female. (B) Confocal microscopic images of pan actin for thoracic aorta VSMCs from old and young of male and female monkeys.

Figure.3 (A) Immunostaining intensity for $\alpha 5 \beta 1$-integrin in cultured VSMCs from thoracic aorta of old (male $\mathrm{n}=11$, female $\mathrm{n}=19$ ) and young (male $\mathrm{n}=17$, female $\mathrm{n}=16$ ) monkeys. ${ }^{*}, \mathrm{P}<0.05$ old versus young monkeys. p>0.05 male vs female. (B) Confocal microscopic images of $\alpha 5 \beta 1$ integrin for thoracic aorta VSMCs from old and young of male and female monkeys.

Figure.4 (A) Elasticity values measured by AFM in VSMCs from thoracic aorta of old (male $\mathrm{n}=11$, female $\mathrm{n}=10$ ) and young (male $\mathrm{n}=6$, female $\mathrm{n}=8$ ) monkeys. $*, \mathrm{P}<0.05$ old versus young monkeys. $p>0.05$ male vs female. (B) $\alpha 5 \beta 1$-integrin adhesion to the extracellular matrix (ECM) protein fibronectin (FN) on the surface VSMC from thoracic aorta of old (male $\mathrm{n}=11$, female $\mathrm{n}=11$ ) and young (male $\mathrm{n}=6$, female $\mathrm{n}=6$ ) monkeys by AFM adhesion force measurement. *, $\mathrm{P}<$ 0.05 old versus young monkeys. $\mathrm{p}>0.05$ male vs female. 
(A)

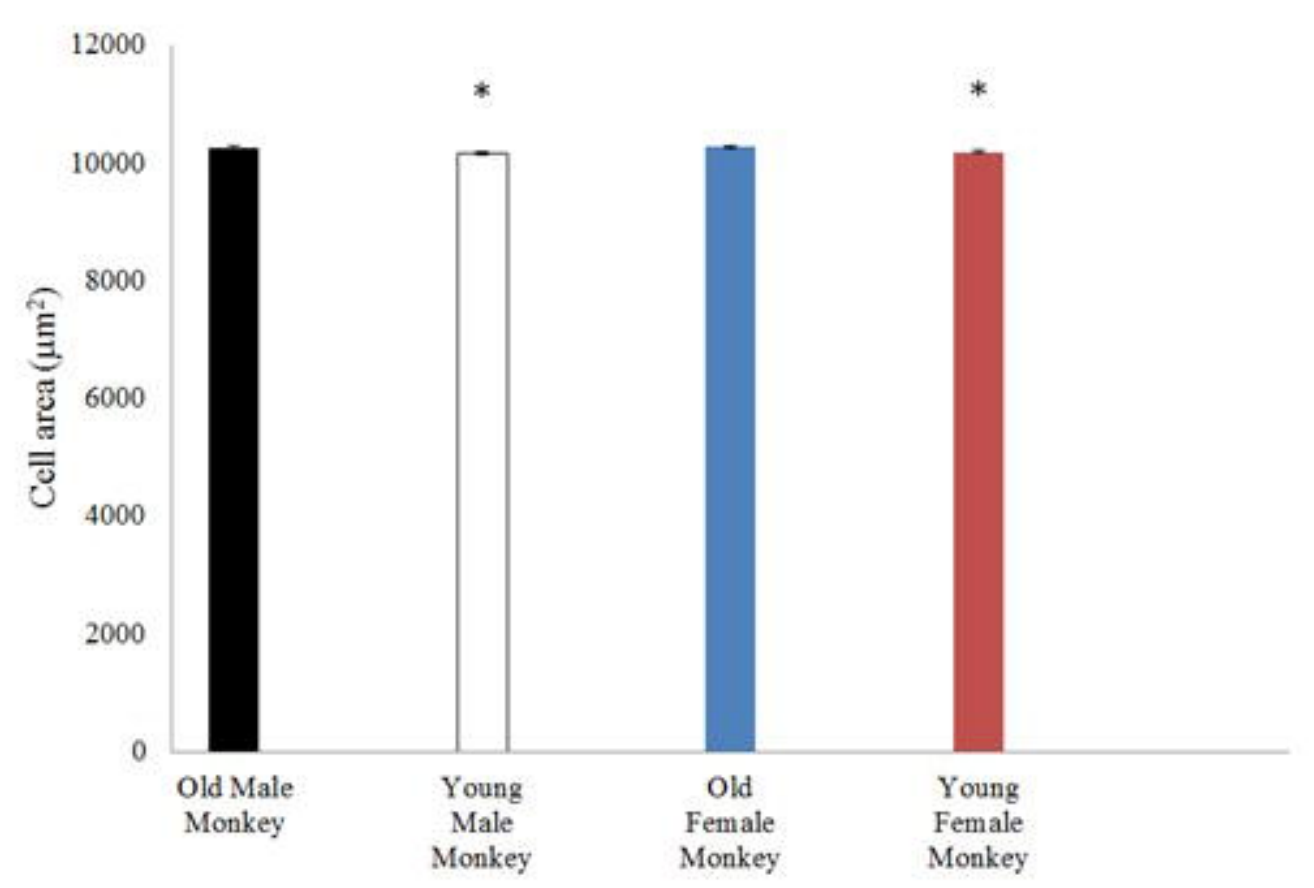

(C)

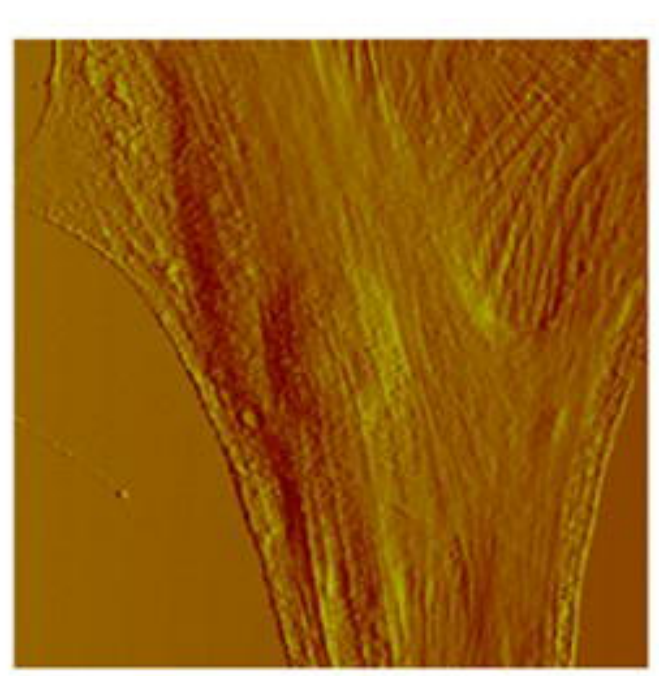

Old Male monkey TA VSMC
(B)

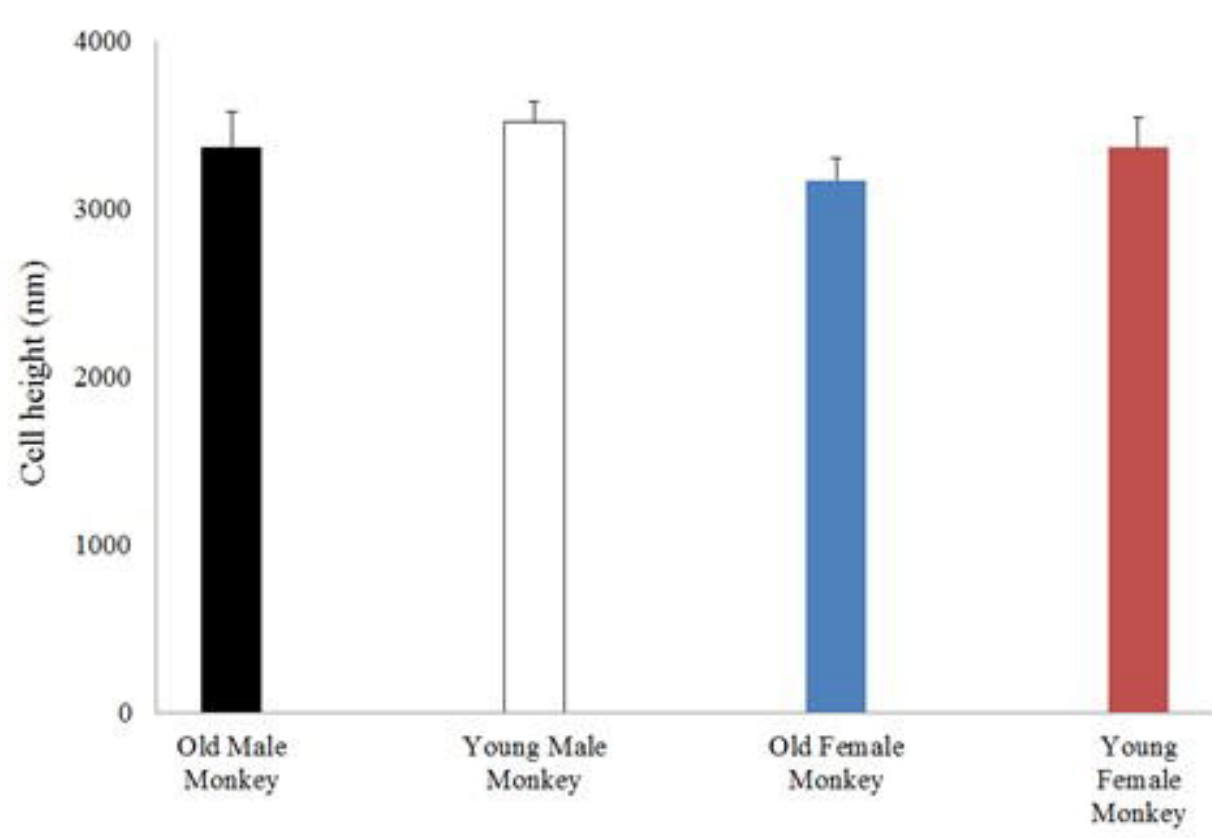

(D)
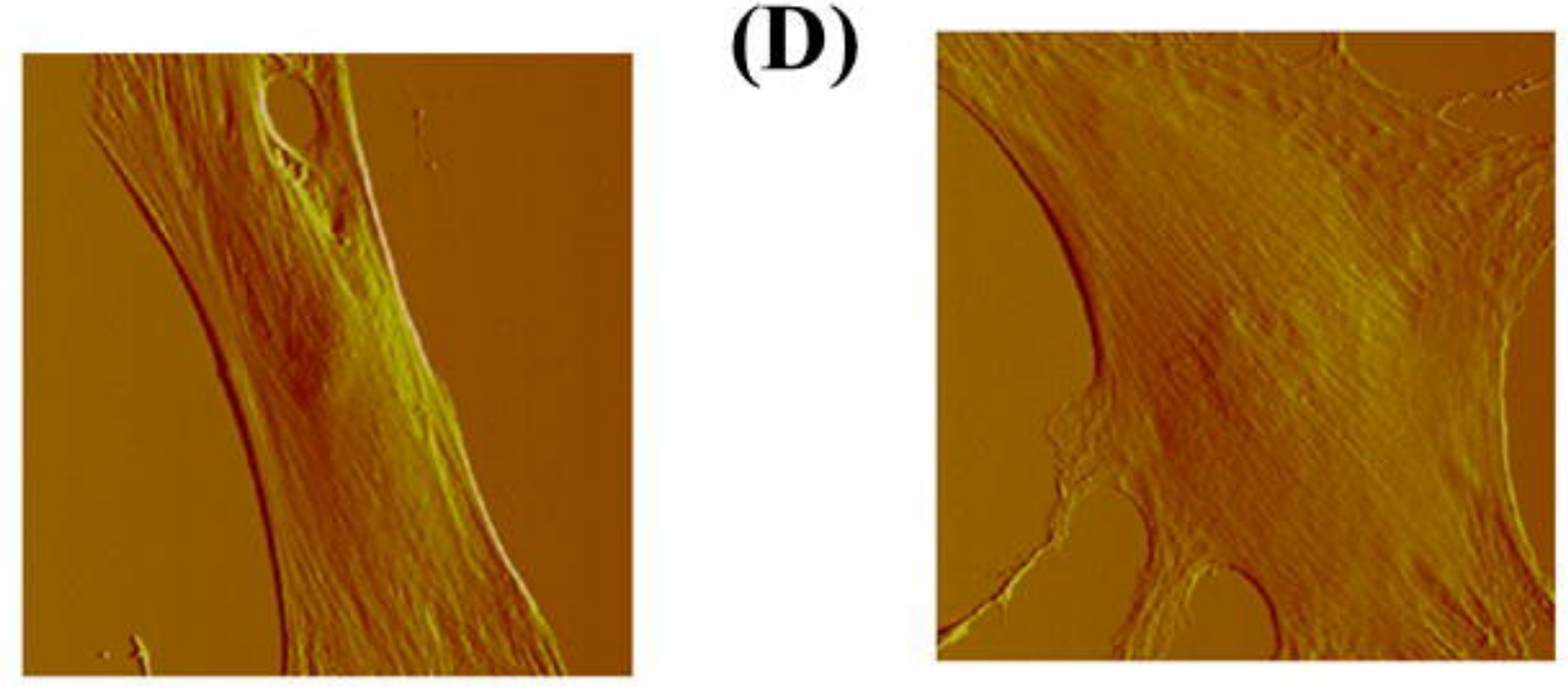

Old Female monkey TA VSMC Young Female monkey TA VSMC

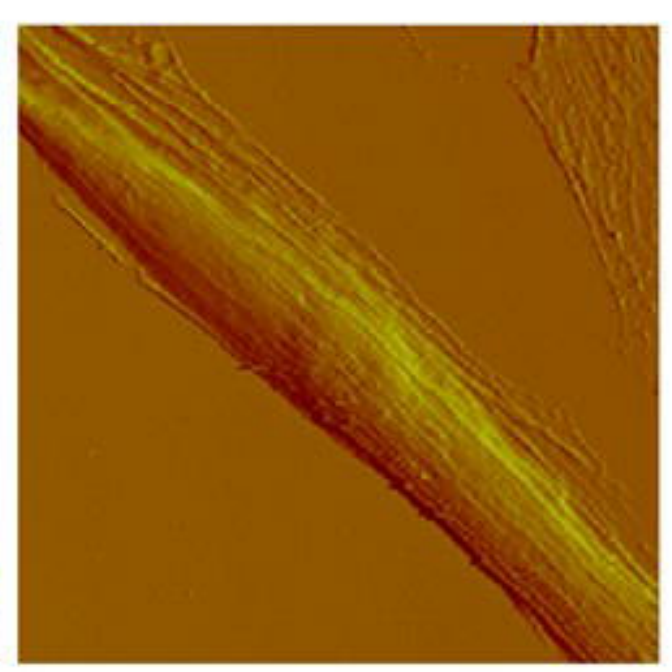



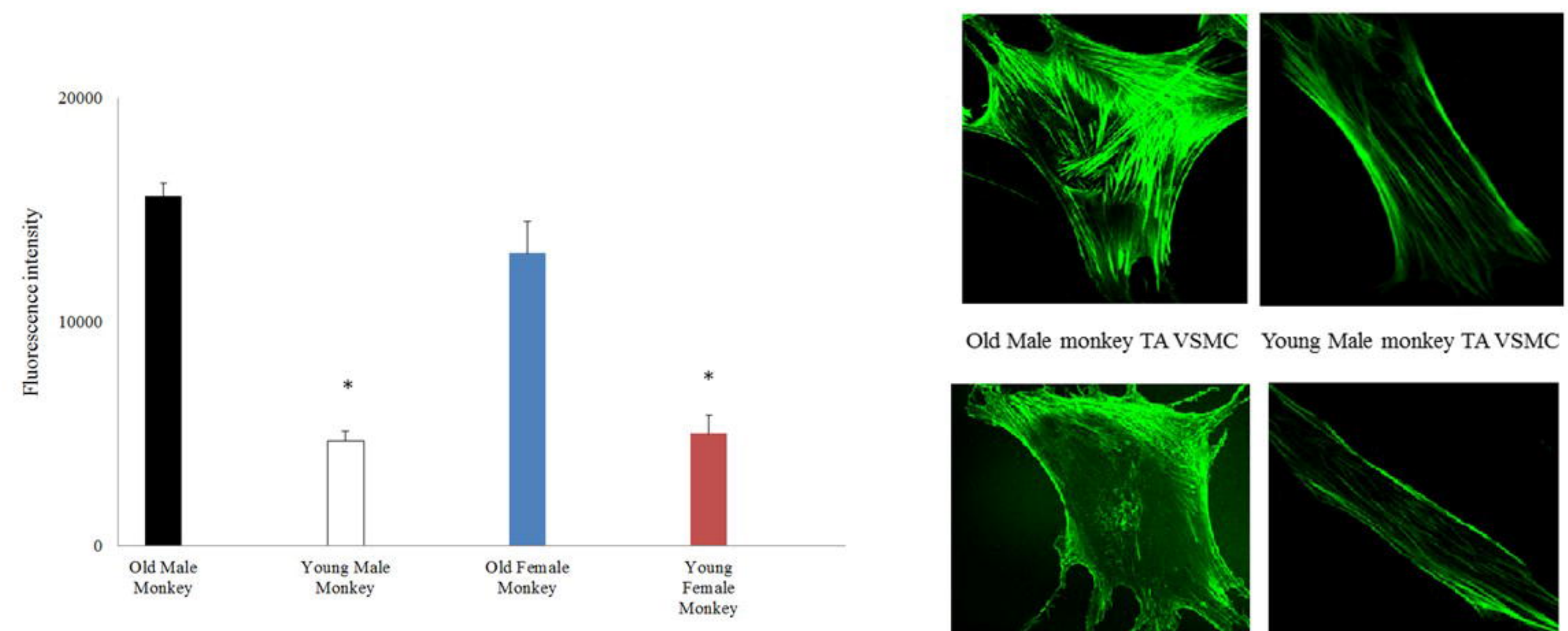

Old Male monkey TA VSMC Young Male monkey TA VSMC
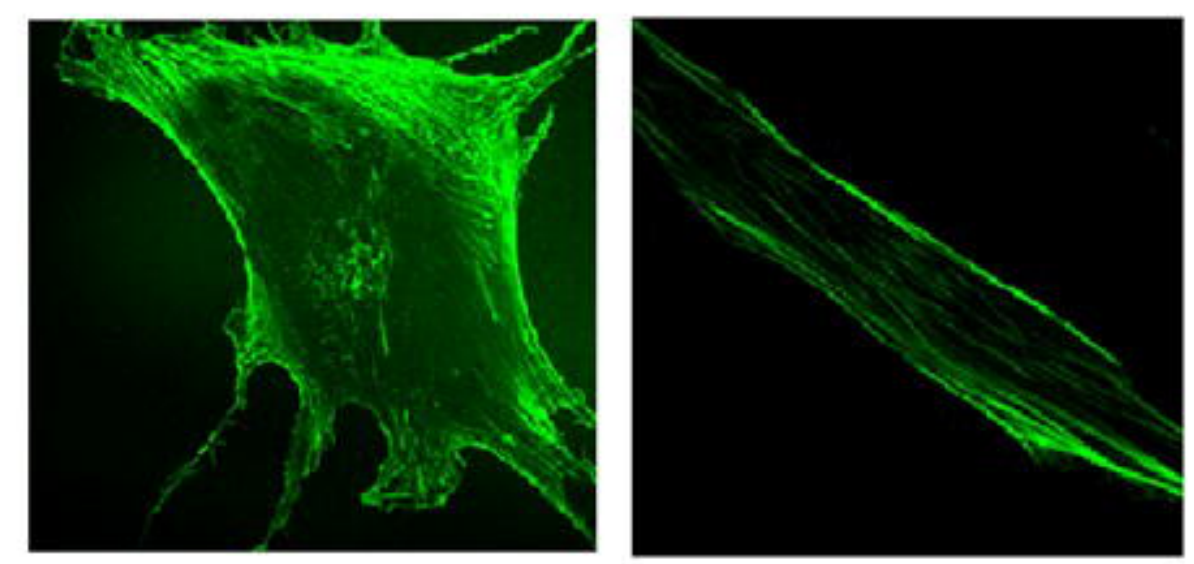

Old Female monkey TAVSMC Young Female monkey TA VSMC

(A)

(B) 

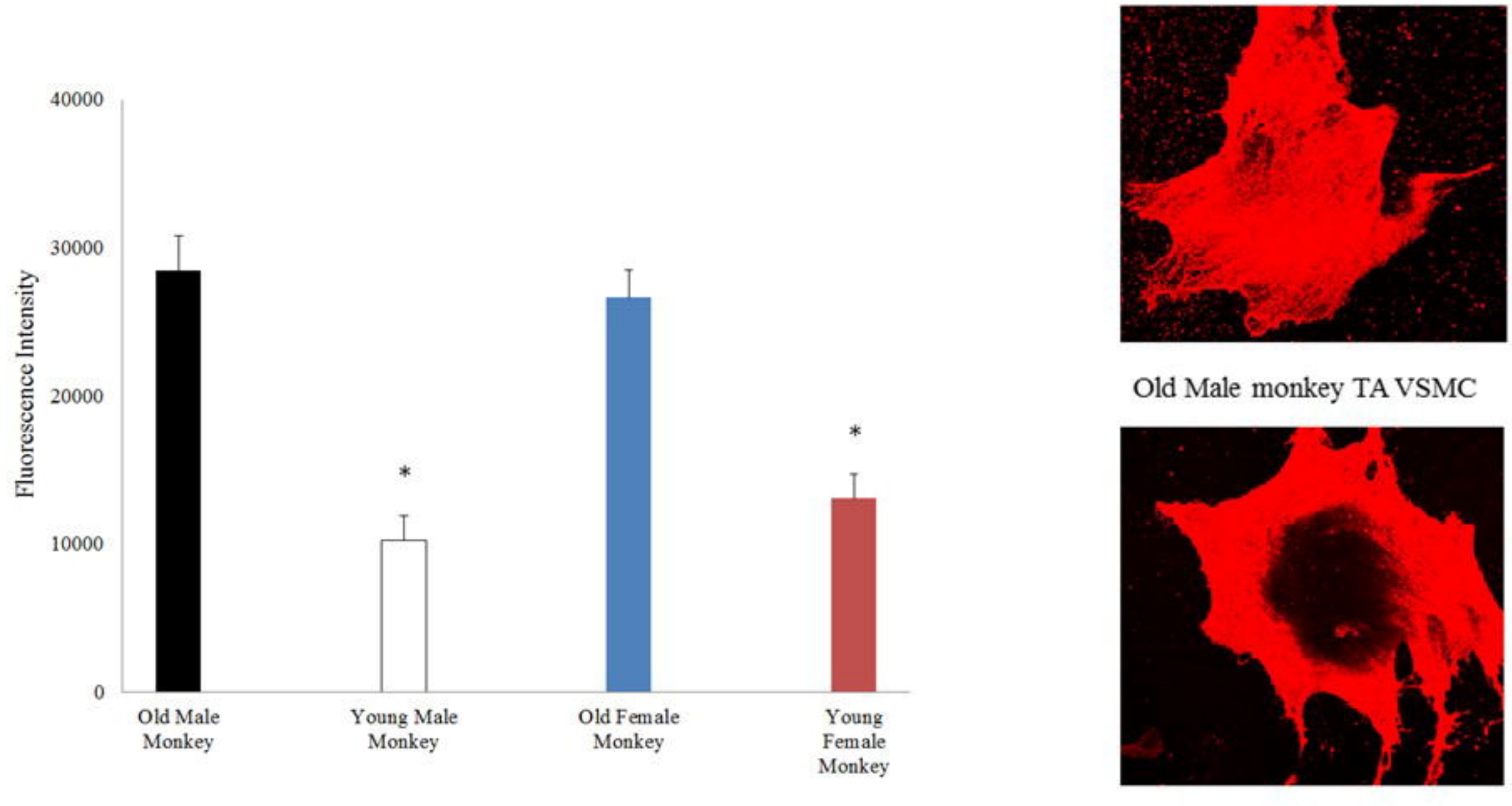

Old Male monkey TA VSMC

Young Male monkey TA VSMC
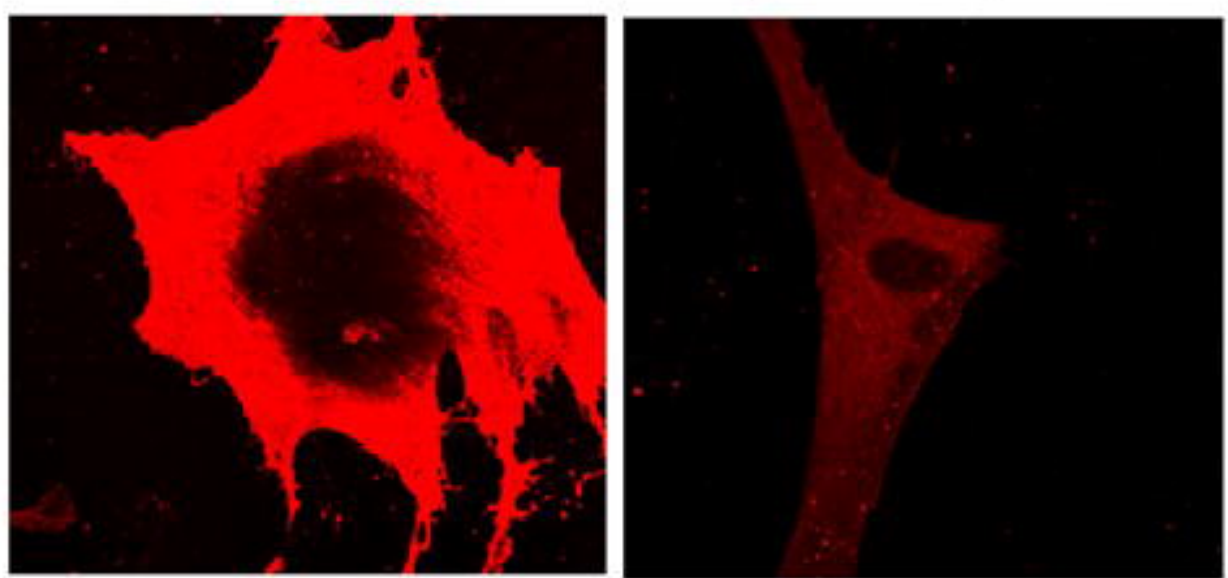

Old Female monkey TA VSMC Young Female monkey TAVSMC 

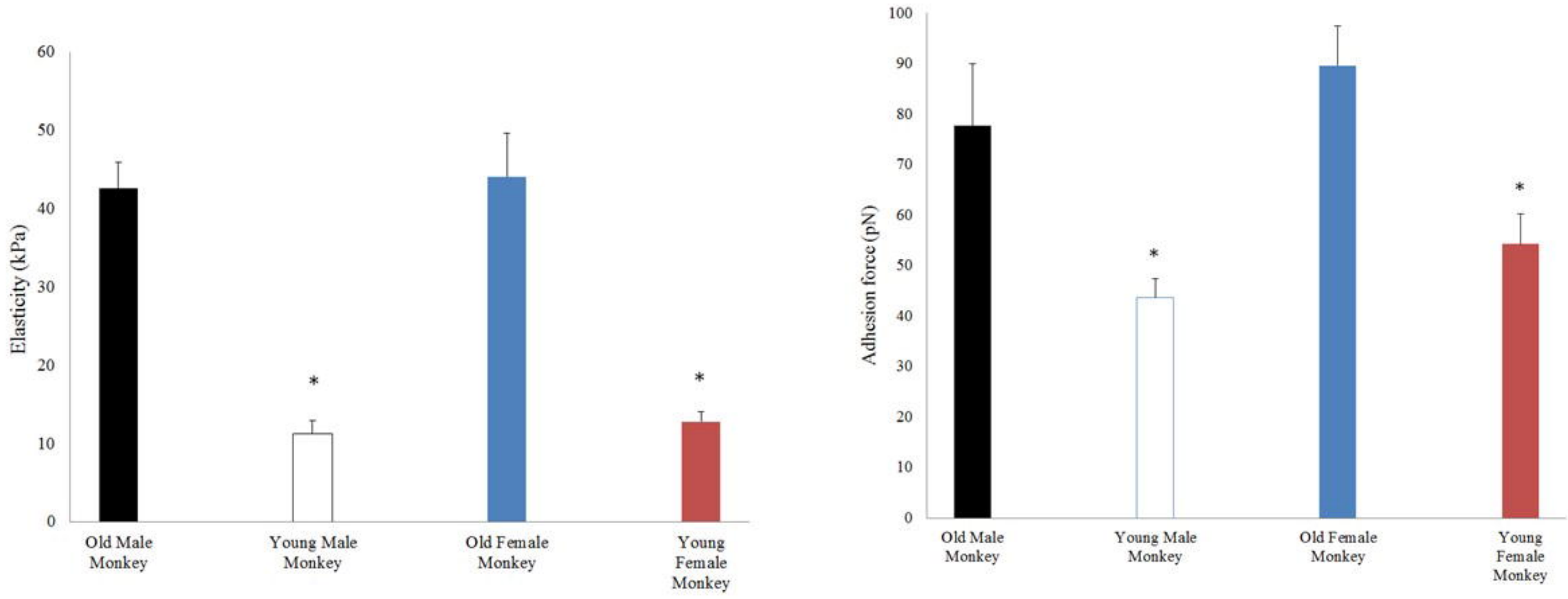

(A)

(B) 